\title{
Bone morphogenetic protein-7 upregulates genes associated with osteoblast differentiation, including collagen I, Sp7 and IBSP in gingiva-derived stem cells
}

\author{
HYUNJIN LEE ${ }^{1 *}$, SAE KYUNG MIN ${ }^{1 *}$, YOUNGMIN SONG ${ }^{1}$, YUN-HEE PARK ${ }^{2}$ and JUN-BEOM PARK ${ }^{1}$ \\ ${ }^{1}$ Department of Periodontics, College of Medicine, The Catholic University of Korea, \\ Seoul 06591; ${ }^{2}$ Ebiogen Inc., Seoul 07282, Republic of Korea
}

Received August 2, 2018; Accepted July 19, 2019

DOI: $10.3892 /$ etm.2019.7904

\begin{abstract}
The present study was performed to evaluate the effects of short-term application of bone morphogenetic protein-7 (BMP-7) on human gingiva-derived mesenchymal stem cells with next-generation sequencing. Human gingiva-derived stem cells were treated with a final concentration of $100 \mathrm{ng} / \mathrm{ml}$ BMP-7 and the same concentration of a vehicle control. mRNA sequencing and data analysis were performed along using gene ontology and pathway analysis. RT-qPCR of mRNA of collagen I, Sp7, IBSP and western blot analysis of collagen I, osterix and bone sialoprotein was also performed. A total of 25,737 mRNAs were identified to be differentially expressed. Regarding osteoblast differentiation, 14 mRNAs were upregulated and 10 were downregulated when the results of the BMP-7 at $3 \mathrm{~h}$ were compared with the control at $3 \mathrm{~h}$. The expression of collagen I was increased following the application of BMP-7 at $3 \mathrm{~h}$, and this increase was also observed following western blot analysis. The effects of BMP-7 on stem cells were evaluated with mRNA sequencing, and the expression was validated with RT-qPCR and western blot analysis. The short-term application of BMP-7 produced an increased expression of collagen I, which was associated with target genes selected for osteoblast differentiation. This study may provide novel insights into the role of BMP-7 using mRNA sequencing.
\end{abstract}

\section{Introduction}

Bone morphogenetic proteins (BMP) are reported to be associated with proliferation and differentiation of numerous types

Correspondence to: Professor Jun-Beom Park, Department of Periodontics, College of Medicine, The Catholic University of Korea, 222 Banpo-daero, Seoul 06591, Republic of Korea

E-mail: jbassoonis@yahoo.co.kr

${ }^{*}$ Contributed equally

Key words: bone morphogenetic protein 7, cell differentiation, gingival, osteogenesis, stem cells of cells $(1,2)$. In a previous in vitro study, bone morphogenetic protein-7 (BMP-7) was shown to promote odontogenic differentiation of stem cells derived from dental pulp (3). BMP-7 at concentrations of 50 and $100 \mathrm{ng} / \mathrm{ml}$ was shown to produce dental pulp stem cells that tended toward odontogenic differentiation through the Smad5 signaling pathway and did not significantly interrupt cell proliferation in vitro (3). A previous report showed that BMP-7 made the fibroblasts derived from a human dermis differentiate into osteoblasts and promoted osteogenesis (4). Similarly, BMP-7 enhanced the human-induced pluripotent stem cells' differentiation potential (5).

Mesenchymal stromal cells from intraoral region drew great attention in tissue regeneration because they can be achieved with a minimally invasive maneuver (6). For several years, gingiva-derived stem cells have been used for various purposes (7-9). Mesenchymal gingiva-derived stem cells repaired calvarial and mandibular defects, and gingival tissue can serve as a source for stem cell therapy (10). Gingiva-derived stem cells can aggregate into tight three-dimensional spheroids, which can produce their own matrix (8). Gingiva-derived stem cells have demonstrated to have immunoregulatory effects by promoting Treg cell polarization, inducing T-cell apoptosis and suppressing the in vitro polarization of Th17 cell (9). Gingiva-derived stem cells encapsulated in an alginate/hyaluronic acid three-dimensional scaffold have been applied (7). Gingiva-derived stem cells have been used for bone and nerve regeneration (11). This study was aimed at examining the time-dependent impact of BMP-7 on changes of gene expression in the stem cells. mRNA sequencing and data analysis were performed along with gene ontology and pathway analysis. Quantitative analysis of mRNA using real-time polymerase chain reactions of ColI, Sp7 and IBSP and western blot analysis of collagen I, osterix and bone sialoprotein as well as $\beta$-actin were performed. The purpose of this study was to demonstrate the effects of BMP-7 on the gingiva-derived stem cells.

\section{Materials and methods}

Stem cells collected from human gingivae. Human gingivae were collected from healthy participants following the method used in a previous study (12). Approval of this study was obtained from the Institutional Review Board at Seoul St 
Mary's Hospital (KC18SESI0199). The participants signed the written consent, and all of the procedures completed in this study followed the relevant regulations and guidelines.

Concisely, de-epithelialization of the obtained tissues was performed, and the tissues were dissected into 1-2- $\mathrm{mm}^{2}$ fragments. The tissues were dissolved using collagenase type IV (Sigma-Aldrich Co., St. Louis, MO, USA) at $2 \mathrm{mg} / \mathrm{ml}$ and dispase (Sigma-Aldrich Co.) at $1 \mathrm{mg} / \mathrm{ml}$. The resultant products was filtered with a 70- $\mu$ m cell strainer (Falcon, BD Biosciences, Franklin Lakes, NJ, USA), and sterile phosphate-buffered saline (PBS, Welgene, Daegu, Korea) was applied to remove the non-adherent cells after incubation for $24 \mathrm{~h}$.

Treatment of the stem cells with BMP-7. The gingivae-derived stem cells were then treated with BMP-7 (CYT-333; ProSpec Co., Nagoya, Japan) at a final concentration of $100 \mathrm{ng} / \mathrm{ml}$. The control group was loaded with the same concentration of the dissolving media of acetic acid. The cells were obtained at 3 or $24 \mathrm{~h}$.

Evaluation of the secretion of human vascular endothelial growth factor for paracrine effect. Secretion of human vascular endothelial growth factor was determined at 3 and $24 \mathrm{~h}$ using a kit (Quantikine ${ }^{\circledR}$ ELISA, cat. no. DVE00; R\&D Systems, Inc., Minneapolis, MN, USA). Preparation of the samples and reagents were performed following the manufacturer's recommendations. The resulting products were diluted ten times. The differences of absorbance levels at 450 and $570 \mathrm{~nm}$ were used for the evaluation of paracrine effects.

RNA isolation. Isolation of total RNA was done using Trizol reagent (Invitrogen Corp., Carlsbad, CA, USA). Quality of RNA was evaluated by bioanalyzer (Agilent 2100; Agilent Technologies, Amstelveen, The Netherlands) using the nanochip (RNA 6000, Agilent Technologies), and quantification of RNA was carried out using a spectrophotometer (ND-2000, Thermo Fisher Scientific Inc., Waltham, MA, USA).

Library preparation and sequencing. Library of control and test RNAs were built using SMARTer Stranded RNA-Seq Kit (Clontech Laboratories, Inc., Palo Alto, CA, USA) following the manufacturer's instructions. Concisely, each $2 \mu \mathrm{g}$ total RNA was prepared and reacted with magnetic beads coated with oligo-dT. Washing solution was used to remove other RNAs except mRNA. Initiation of library production was performed by the random hybridization of starter/stopper heterodimers to the poly(A) RNA still attached to the magnetic beads. Illumina-compatible linker sequences were part of these starter/stopper heterodimers. The starter was extended to the next hybridized heterodimer by a single-tube reverse transcription and ligation reaction. The stopper ligated the newly-synthesized cDNA insert. The library was released by second strand synthesis from the beads and the library was amplified with introduction of barcodes. Paired-end 100 sequencing performed high-throughput sequencing using HiSeq 2500 (Illumina, Inc., San Diego, CA, USA).

Data analysis. TopHat software tool was used to map mRNA-Seq reads tool in order to gain the alignment file (13). Counts from unique and multiple alignments were used to determine differentially expressed gene from coverage in Bedtools (14). Quantile-quantile normalization method was applied to process the read count data were processed from EdgeR within Rusing Bioconductor (15). Cufflinks were used for assembling transcripts, estimating their abundances and revealing differential expression of genes or isoforms with the alignment files. The expression level of the gene regions was determined by applying method of fragments per kilobase of exon per million fragments. Gene classification was based on searches performed by DAVID (http://david.abcc.ncifcrf. gov/) (16). Pathway analysis was performed on differentially expressed genes basted on the Kyoto encyclopedia of genes and genome pathway databases (17).

Quantification by real-time polymerase chain reaction. Total RNA was isolated from cultured stem cells using Trizol (Invitrogen Corp.) and was reverse transcribed. Primer sequences were as follows: Collagen I Forward 5':CCAGAA GAACTGGTACATCAGCAA-3', Reverse 5':CGCCATACT CGAACTGGAATC-3', Sp7 Forward 5':TTGCCAATCACT CTCTTTACC-3', Reverse 5': GAGATACCCAAGCCCAGA AT-3', IBSP Forward 5':AGGACTGCCAGAGGAAGCAA-3', Reverse 5': CACAGGCCATTCCCAAAATG-3' and $\beta$-actin Forward 5': TGGCACCCAGCACAATGAA-3' and Reverse 5': CTAAGTCATAGTCCGCCTAGAAGCA-3'. The housekeeping gene was $\beta$-actin in this study, which was used for normalization. SYBR Green Real-Time PCR Master Mixes (Applied Biosystems, Carlsbad, CA, USA) was used to detect mRNA expression through a real-time polymerase chain reaction following the manufacturer's manual.

Western blot analysis. Samples were rinsed with ice-cold PBS twice and treated with a lysis buffer at 3 and $24 \mathrm{~h}$ for $30 \mathrm{~min}$. The lysates were centrifuged at $13,500 \mathrm{rpm}$ for 15 min at $4^{\circ} \mathrm{C}$. Separation of the samples were performed by gel electrophoresis (Mini-PROTEAN ${ }^{\circledR}$ TGX $^{\mathrm{TM}}$ Precast Gels; Bio-Rad, Hercules, CA, USA), transblotted to the membranes (Immun-Blot ${ }^{\circledR}$; Bio-Rad) and immunoblotted with the corresponding antibodies and the detection kits. Primary antibodies against collagen I (ab6308; Abcam, MA, USA), RUNX2 (ab76956; Abcam), OCN (ab13418; Abcam), Sp7 transcription factor (ab22552; Abcam), bone sialoprotein (ab52128, Abcam), $\beta$-actin (SC-516102; Santa Cruz Biotechnology, Inc., Dallas, TX, USA) and secondary antibodies were purchased from Santa Cruz Biotechnology. The protein expressions of Collagen I, Sp7, bone sialoprotein and $\beta$-actin was quantitatively analyzed using with image processing program (ImageJ, National Institutes of Health, Bethesda, MD, USA).

Alkaline phosphatase activity. In the test groups, the stem cells were treated with BMP-7 for 3 or $24 \mathrm{~h}$. Then media were changed to osteogenic media composed of $\alpha$-MEM (Gibco, Grand Island, NY, USA), containing $200 \mathrm{mM}$ of L-glutamine (Sigma-Aldrich Co.), $10 \mathrm{mM}$ of ascorbic acid 2-phosphate (Sigma-Aldrich Co.), $100 \mu \mathrm{g} / \mathrm{ml}$ of streptomycin (Sigma-Aldrich Co.), 15\% fetal bovine serum (Gibco), $100 \mathrm{U} / \mathrm{ml}$ of penicillin, $2 \mathrm{mg} / \mathrm{ml}$ of glycerophosphate disodium salt hydrate, and $38 \mu \mathrm{g} / \mathrm{ml}$ of dexamethasone. A commercially available kit (K412-500; BioVision, Inc., 
A

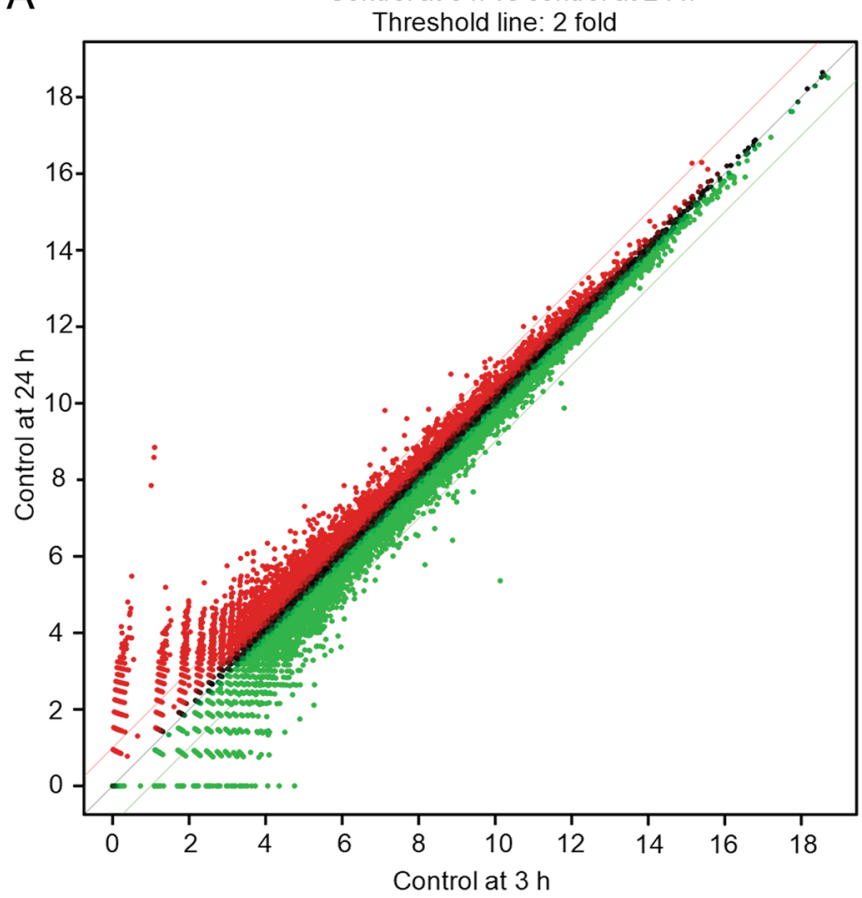

C

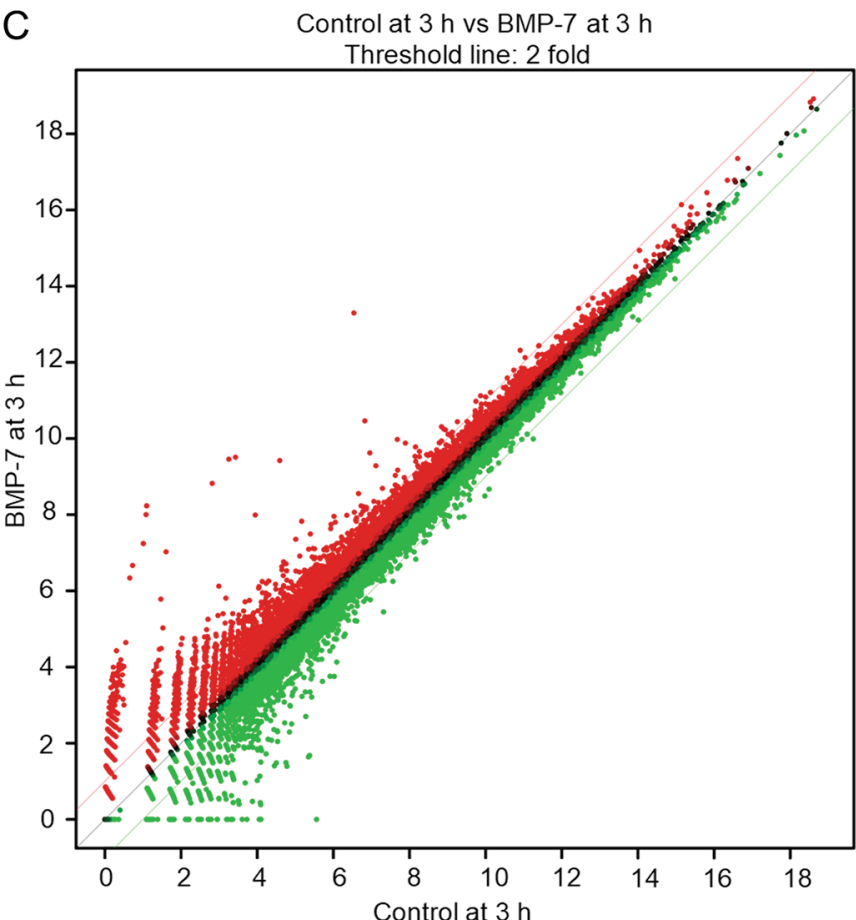

B BMP-7 at $3 \mathrm{~h}$ vs BMP-7 at $24 \mathrm{~h}$ Threshold line: 2 fold

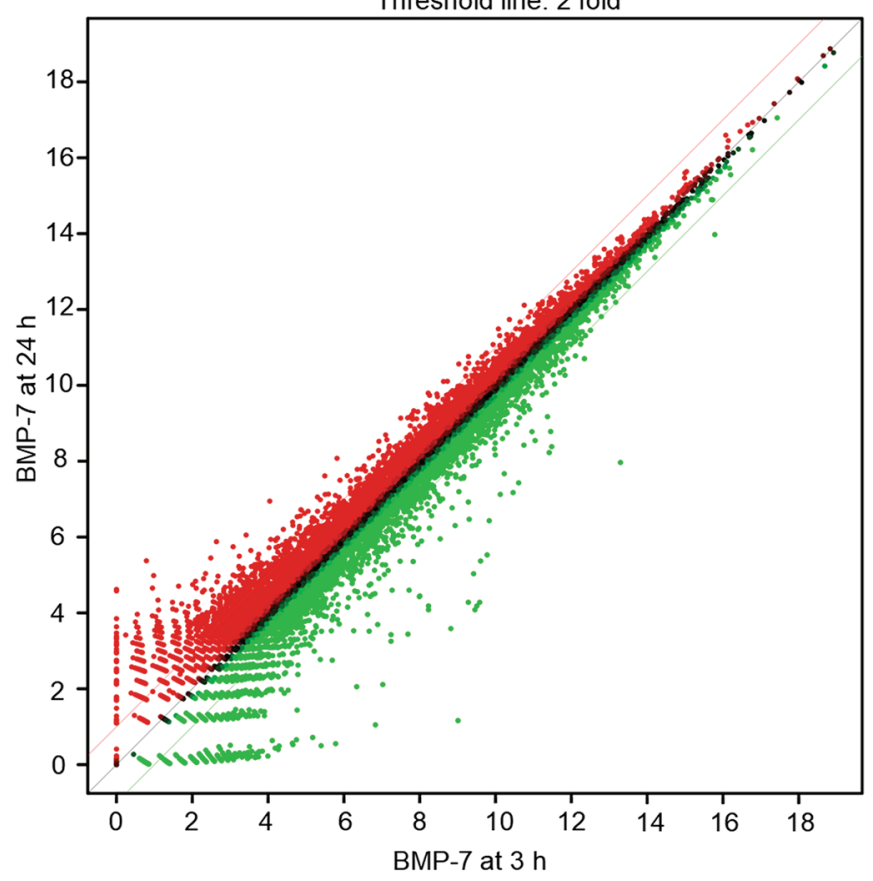

D Control at $24 \mathrm{~h}$ vs BMP-7 at $24 \mathrm{~h}$

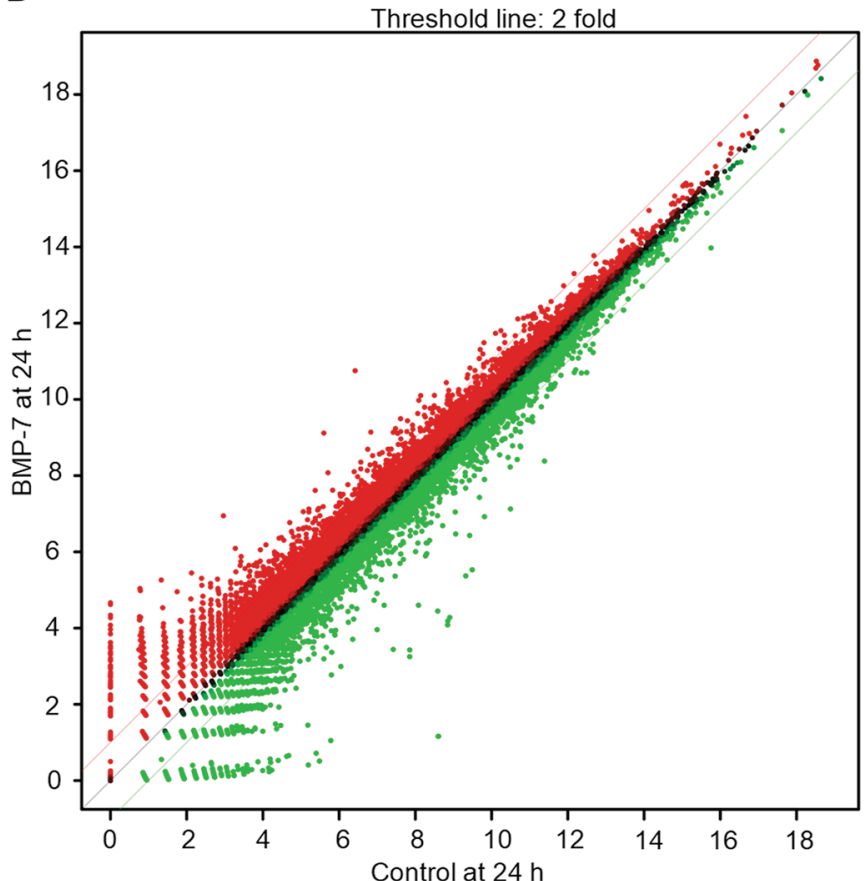

Figure 1. Scatter plot showing the expression of untreated control at 3 and 24 h BMP-7 treated for 3 and 24 h (x,y-axis: Relative expression level, red: Expression level of $y$-value is higher than expression level of x-value, green: Expression level of y-value is lower than expression level of $x$-value). (A) Control at $24 \mathrm{~h} /$ control at $3 \mathrm{~h}$. (B) BMP-7 at $24 \mathrm{~h} / \mathrm{BMP}-7$ at $3 \mathrm{~h}$. (C) BMP-7 at $3 \mathrm{~h} / \mathrm{control}$ at $3 \mathrm{~h}$. (D) BMP-7 at $24 \mathrm{~h} / \mathrm{control}$ at $24 \mathrm{~h}$. BMP-7, bone morphogenetic protein 7 ..

Milpitas, CA, USA) were used for the analysis of alkaline phosphatase activity on Day 7.

Statistical analysis. The data were presented as mean \pm standard deviations of the results. A test of normality was conducted with Shapiro-Wilk, and differences among the groups were analyzed by one-way analysis of variance with Tukey's post hoc test using a statistical package (SPSS 12 for
Windows; SPSS Inc., Chicago, IL, USA).P $<0.05$ was considered to indicate a statistically significant difference.

\section{Results}

Evaluation of gene ontology and pathway analysis. Differentially expressed mRNAs in this study is a total of 25,737 . The scatter plots displaying differentially expressed 

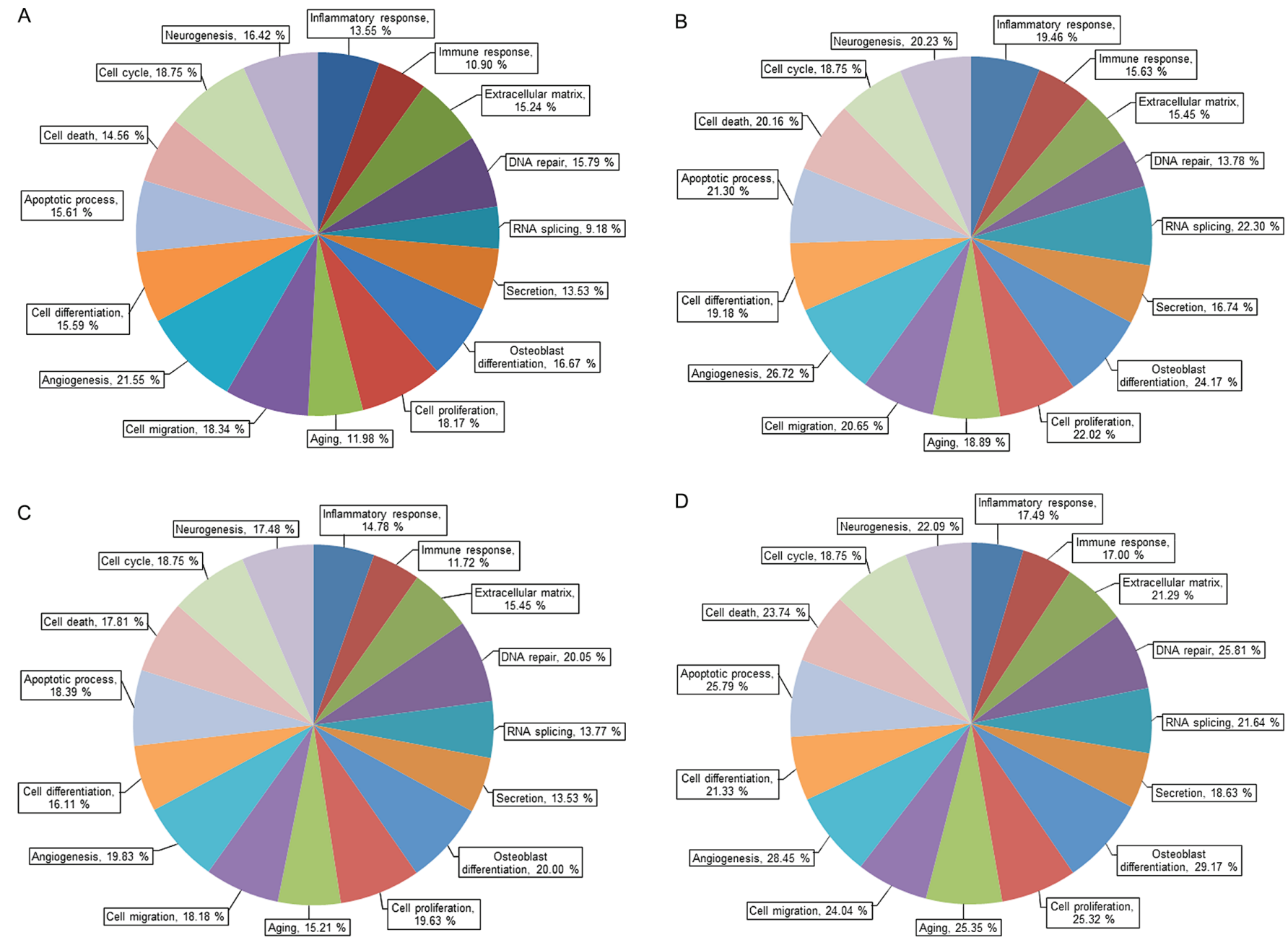

Figure 2. Gene ontology analysis of mRNA expression categorized by its importance (fold change of 1.3 or greater, $\log 2$ normalized read counts $\geq 4$ were selected). (A) Control at $24 \mathrm{~h} / \mathrm{control}$ at $3 \mathrm{~h}$. (B) BMP-7 at $24 \mathrm{~h} / \mathrm{BMP}-7$ at $3 \mathrm{~h}$. (C) BMP-7 at $3 \mathrm{~h} /$ control at $3 \mathrm{~h}$. (D) BMP-7 at $24 \mathrm{~h} / \mathrm{control}$ at $24 \mathrm{~h}$. BMP-7, bone morphogenetic protein 7.

mRNAs, are illustrated in Fig. 1. Gene ontology analysis of mRNA expression is categorized by its importance and the selection criteria were fold change $\geq 1.3$ and $\log 2$ normalized read counts $\geq 4$ (Fig. 2). Fig. 3 shows gene ontology analysis of mRNA expression by upregulation and downregulation (fold change of 1.3 or greater, $\log 2$ normalized read counts of 4 or greater were selected).

The results of differentially expressed mRNA related to osteoblast differentiation, are displayed in Table I. To analyze the effects of incubation time on the cultured cells, the comparisons were performed between the control at 24 and at $3 \mathrm{~h}$. The investigation demonstrated that upregulation was seen in 9 mRNAs and downregulation was noted in 11 mRNAs. Comparisons between BMP-7 at $24 \mathrm{~h}$ and BMP-7 at $3 \mathrm{~h}$ showed that 9 mRNAs were upregulated and 20 were downregulated. Comparisons between BMP-7 at $3 \mathrm{~h}$ and the control at $3 \mathrm{~h}$ exhibited upregulation of 14 mRNAs and downregulation of 10 mRNAs. When the results of BMP-7 at $24 \mathrm{~h}$ were compared with the control at $24 \mathrm{~h}$, upregulation of 14 mRNAs and downregulation of 21 mRNAs were seen.

Secretion of human vascular endothelial growth factor. The results clearly demonstrated that the vascular endothelial growth factor was secreted at 3 and $24 \mathrm{~h}$ irrespective of culture period (Fig. 4). No significant change in secretion of the vascular endothelial growth factor was seen at $3 \mathrm{~h}$ with the addition of bone morphogenetic protein $(P>0.05)$. Similarly, no statistically significant changes were noted with the loading of bone morphogenetic protein at $24 \mathrm{~h}(\mathrm{P}>0.05)$.

Validation of mRNA expression. Quantitative real-time PCR revealed that mRNA levels of collagen I were higher in the 24-h control group than in 3-h control group ( $\mathrm{P}>0.05$; Fig. 5A). Application of BMP-7 increased the expression of collagen I at 3 and $24 \mathrm{~h}$. The results showed that application of BMP-7 at $24 \mathrm{~h}$ produced a decrease of $\mathrm{Sp} 7(\mathrm{P}>0.05 ; \mathrm{Fig}$. $5 \mathrm{~B})$. The results showed that application of BMP-7 at $24 \mathrm{~h}$ showed a decrease of IBSP, but no significant differences were noted $(\mathrm{P}>0.05$; Fig. 5C).

Western blot analysis. Western blot analysis was done to analyze protein expression of collagen I, Sp7 and bone sialoprotein following the application with BMP-7 at 3 and $24 \mathrm{~h}$ compared with the untreated control group at 3 and $24 \mathrm{~h}$ (Fig. 6A). Normalization of the protein expressions showed that the control at $24 \mathrm{~h}$ showed $88.4 \pm 31.8 \%$ expression 

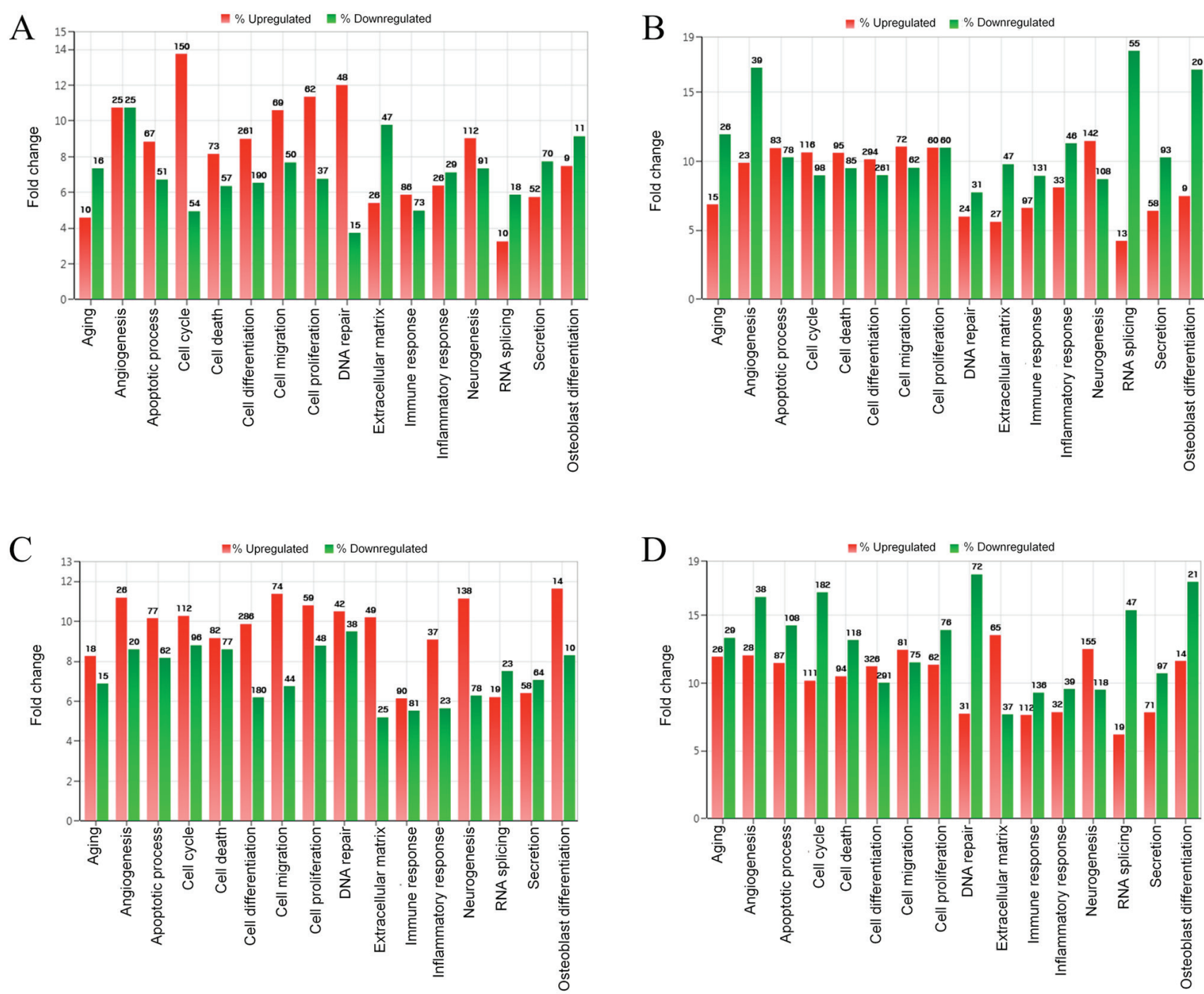

Figure 3. Gene ontology analysis of mRNA expression by up- and downregulation (fold change of 1.3 or greater, $\log 2$ normalized read counts $\geq 4$ were selected). (A) Control at $24 \mathrm{~h} /$ control at $3 \mathrm{~h}$. (B) BMP-7 at $24 \mathrm{~h} / \mathrm{BMP}-7$ at $3 \mathrm{~h}$. (C) BMP-7 at $3 \mathrm{~h} /$ control at $3 \mathrm{~h}$. (D) BMP-7 at $24 \mathrm{~h} / \mathrm{control}$ at $24 \mathrm{~h}$. BMP-7, bone morphogenetic protein 7.

of collagen I, and the group treated with BMP-7 yielded $154.5 \pm 8.2 \%$ and $75.1 \pm 16.0 \%$ of expression of collagen $\mathrm{I}$ at 3 and $24 \mathrm{~h}$, respectively, compared to control values at $3 \mathrm{~h}$ as a baseline of $100 \%(100.0 \pm 14.3 \%)(\mathrm{P}>0.05$, Fig. 6B).

The expression of Sp7 in the control group at $24 \mathrm{~h}$ did not show significant change compared with the control at $3 \mathrm{~h}$. Normalization of the protein expressions revealed that the control at $24 \mathrm{~h}$ showed $86.8 \pm 20.7 \%$ expression of Sp7, and the group treated with BMP-7 yielded $93.2 \pm 40.6 \%$ and $75.4 \pm 13.9 \%$ of expression of $\mathrm{Sp} 7$ at 3 and $24 \mathrm{~h}$, respectively, compared to control values at $3 \mathrm{~h}$ as a baseline of $100 \%(100.0 \pm 3.6 \%)$ ( $\mathrm{P}>0.05$, Fig. 6C).

The relative expression of bone sialoprotein is shown in Fig. 6C. Normalization of the protein expressions demonstrated that the control at $24 \mathrm{~h}$ showed $146.8 \pm 16.4 \%$ expression of bone sialoprotein, and the group treated with BMP-7 yielded $82.5 \pm 15.1 \%$ and $135.1 \pm 9.6 \%$ of expression of bone sialoprotein at 3 and $24 \mathrm{~h}$, respectively, when the control value at $3 \mathrm{~h}$ were considered $100 \%(100.0 \pm 5.0 \%)$. TGF- $\beta$ signaling pathway was associated with the target genes selected for osteoblast differentiation (Fig. 7).

\subsection{5}

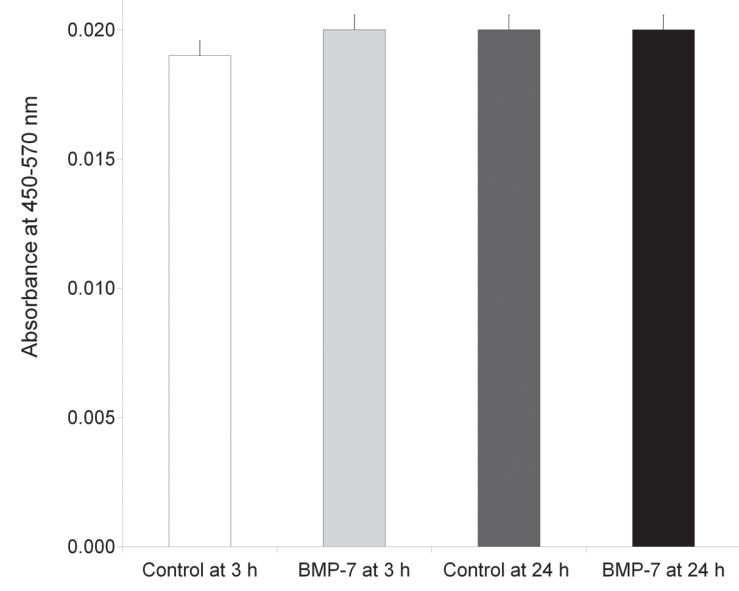

Figure 4. Secretion of vascular endothelial growth factor from gingiva-derived stem cells at 3 and $24 \mathrm{~h}$. No significant changes in secretion of vascular endothelial growth factor were observed following the addition of bone morphogenetic protein at 3 or $24 \mathrm{~h}$. BMP-7, bone morphogenetic protein 7. 
Table I. Differentially expressed mRNA related to osteoblast differentiation (fold change of 1.3 or greater, $\log 2$ normalized read counts $\geq 4$ were selected).

\begin{tabular}{|c|c|c|c|c|c|c|c|}
\hline Gene symbol & $\begin{array}{l}\text { Control-24 h/ } \\
\text { Control-3 h }\end{array}$ & $\begin{array}{l}\text { Gene } \\
\text { symbol }\end{array}$ & $\begin{array}{l}\text { BMP7-24 h/ } \\
\text { BMP7-3 h }\end{array}$ & $\begin{array}{l}\text { Gene } \\
\text { symbol }\end{array}$ & $\begin{array}{l}\text { BMP7-3 h/ } \\
\text { Control-3 h }\end{array}$ & $\begin{array}{c}\text { Gene } \\
\text { symbol }\end{array}$ & $\begin{array}{l}\text { BMP7-24 h/ } \\
\text { Control-24 h }\end{array}$ \\
\hline AMELX & 2.167 & BMP4 & 2.073 & LRRC17 & 3.748 & WNT11 & 3.428 \\
\hline SOX8 & 1.932 & ALPL & 2.069 & WNT11 & 2.907 & ALPL & 2.946 \\
\hline HDAC4 & 1.743 & WNT11 & 1.900 & SOX8 & 2.304 & BMP4 & 2.805 \\
\hline CHRD & 1.523 & SHOX2 & 1.800 & BMP3 & 2.150 & SHOX2 & 2.684 \\
\hline NF1 & 1.478 & RUNX2 & 1.734 & HDAC4 & 1.808 & RUNX2 & 1.829 \\
\hline DNAJC13 & 1.415 & TMSB4Y & 1.592 & AMELX & 1.741 & TWIST1 & 1.723 \\
\hline BMP2 & 1.407 & WNT3 & 1.476 & PTH1R & 1.568 & NOG & 1.709 \\
\hline GLI2 & 1.365 & CREB3L1 & 1.418 & DNAJC13 & 1.447 & SMO & 1.518 \\
\hline SMAD3 & 1.301 & SNAI2 & 1.309 & BMP4 & 1.445 & PTHLH & 1.514 \\
\hline PENK & 0.761 & SMAD3 & 0.752 & NF1 & 1.440 & IFT80 & 1.513 \\
\hline SNAI2 & 0.691 & HSPE1 & 0.731 & VCAN & 1.434 & ITGA11 & 1.390 \\
\hline SEMA7A & 0.655 & IGFBP5 & 0.718 & SHOX2 & 1.400 & WNT3 & 1.389 \\
\hline HSPE1 & 0.654 & FASN & 0.706 & BMP2 & 1.390 & SNAI2 & 1.386 \\
\hline SNAI1 & 0.638 & RSL1D1 & 0.674 & IFT80 & 1.321 & PENK & 1.347 \\
\hline EPHA2 & 0.634 & IGFBP3 & 0.661 & SNAI2 & 0.732 & PHB & 0.749 \\
\hline PTHLH & 0.592 & FHL2 & 0.639 & TMSB4Y & 0.718 & LIMD1 & 0.749 \\
\hline JUNB & 0.585 & FZD1 & 0.636 & JUNB & 0.693 & RSL1D1 & 0.724 \\
\hline IGFBP3 & 0.585 & SYNCRIP & 0.628 & EPHA2 & 0.662 & GLI2 & 0.714 \\
\hline NOG & 0.371 & ALYREF & 0.626 & FBL & 0.659 & SMAD3 & 0.682 \\
\hline \multirow[t]{16}{*}{ ALPL } & 0.312 & MYBBP1A & 0.596 & MEF2D & 0.643 & FBL & 0.680 \\
\hline & & GTPBP4 & 0.579 & NOG & 0.581 & SNAI1 & 0.666 \\
\hline & & AMELX & 0.577 & SEMA7A & 0.516 & SYNCRIP & 0.661 \\
\hline & & SEMA7A & 0.519 & ALPL & 0.444 & FASN & 0.656 \\
\hline & & BMP3 & 0.511 & SNAI1 & 0.439 & FHL2 & 0.638 \\
\hline & & DDX21 & 0.507 & & & MYBBP1A & 0.637 \\
\hline & & MSX2 & 0.440 & & & CHRD & 0.629 \\
\hline & & CBFB & 0.427 & & & FZD1 & 0.623 \\
\hline & & LRRC17 & 0.268 & & & ALYREF & 0.606 \\
\hline & & SOX8 & 0.057 & & & GTPBP4 & 0.562 \\
\hline & & & & & & DDX21 & 0.526 \\
\hline & & & & & & CBFB & 0.519 \\
\hline & & & & & & MSX2 & 0.512 \\
\hline & & & & & & AMELX & 0.464 \\
\hline & & & & & & SEMA7A & 0.409 \\
\hline & & & & & & SOX8 & 0.068 \\
\hline
\end{tabular}

Alkaline phosphatase activity. The data of the alkaline phosphatase activity assays at Day 7 are demonstrated in Fig. 8. The absorbance values at $405 \mathrm{~nm}$ at Day 7 for control at $3 \mathrm{~h}, \mathrm{BMP}-7$ at $3 \mathrm{~h}$, control at $24 \mathrm{~h}$ and BMP-7 at $24 \mathrm{~h}$ were $0.060 \pm 0.002,0.061 \pm 0.001,0.062 \pm 0.001$, and $0.062 \pm 0.001$, respectively $(\mathrm{P}>0.05)$.

\section{Discussion}

In this report, we evaluated the effects of BMP-7 on stem cells under predetermined concentrations at 3 and $24 \mathrm{~h}$. mRNA sequencing and validation of the expression was done with qualitative real-time PCR and Western blot analysis. It was seen that the application of BMP-7 produced increased expression of collagen I of human gingiva-derived mesenchymal stem cells.

Application with gingiva-derived stem cell inhibited macrophage foam cell formation and reduction of inflammatory macrophage activation (18). Previous reports showed that long incubation of gingiva-derived stem cells lead to neural precursor cells in vitro (19). Three-dimensional bioprinted constructs made with gingiva-derived stem cells promoted facial nerve regeneration (8).

BMP-7 expressing stem-cell sheets were applied in the previous studies (20-22). In a previous report, BMP-7 overexpressing adenovirus vector was used to transfect 

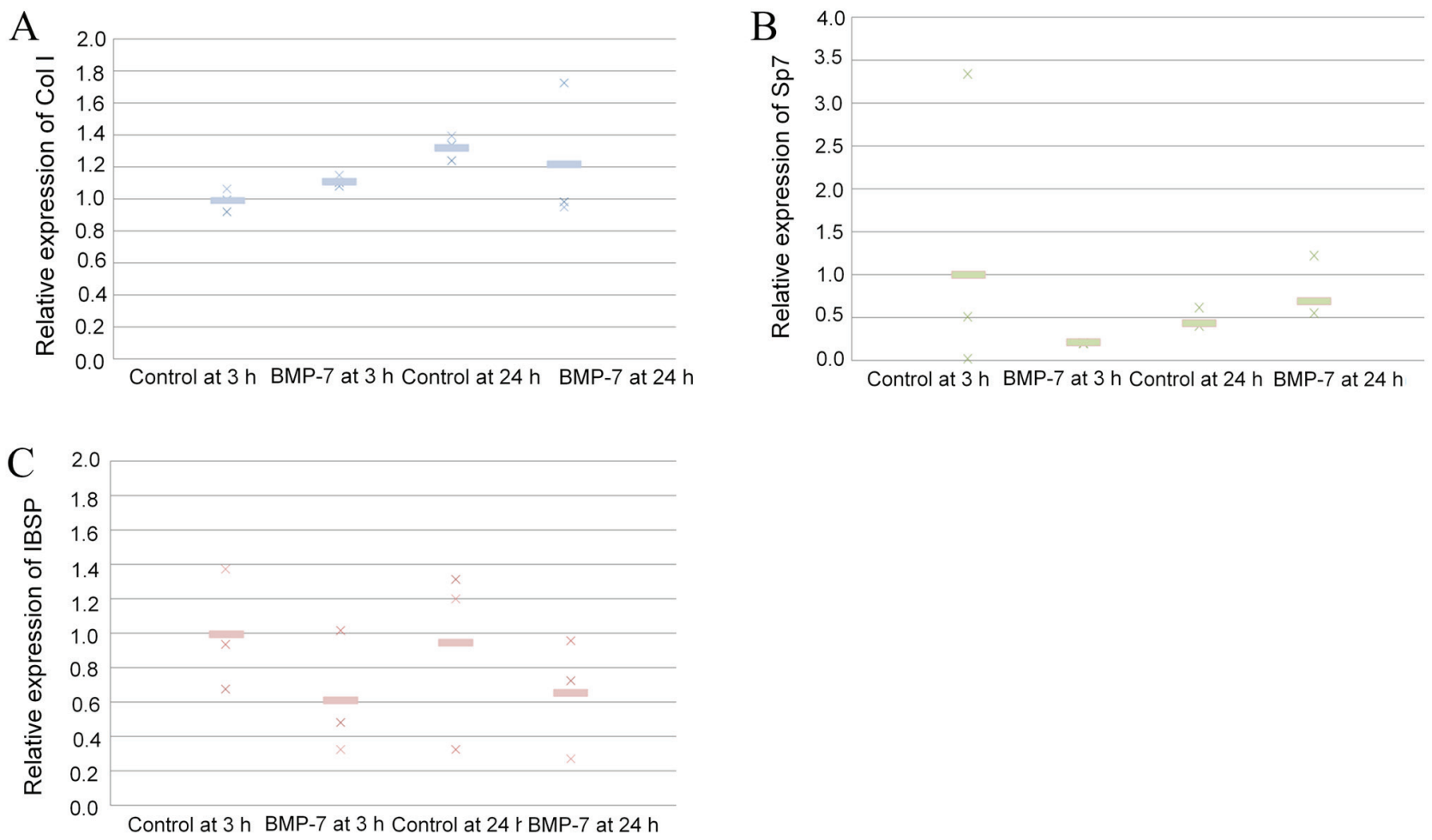

Figure 5. Validation of Collagen I, Sp7 and IBSP. (A) Expression of Collagen I. Application of BMP-7 increased the expression of collagen I at 3 h. (B) Expression of Sp7. Application of BMP-7 at $24 \mathrm{~h}$ produced a decrease of Sp7 but no statistical differences were seen. (C) Expression of IBSP. The results showed that application of BMP-7 at $24 \mathrm{~h}$ showed a decrease of IBSP; however, no statistically significant differences were detected. BMP-7, bone morphogenetic protein 7.

A

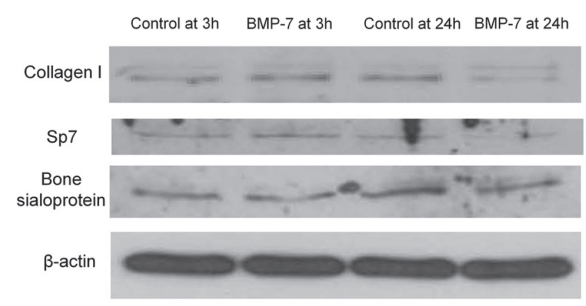

C

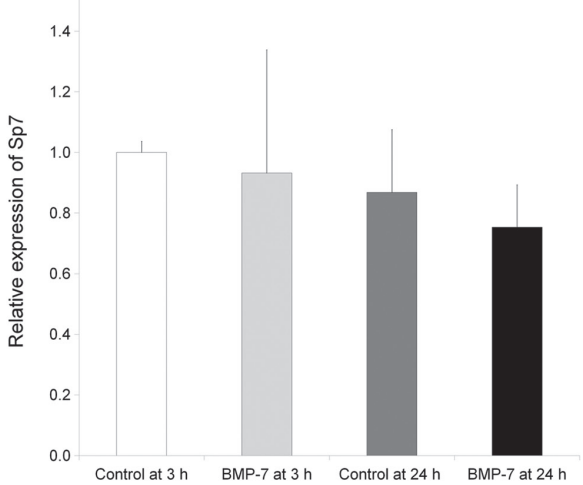

B 1.8

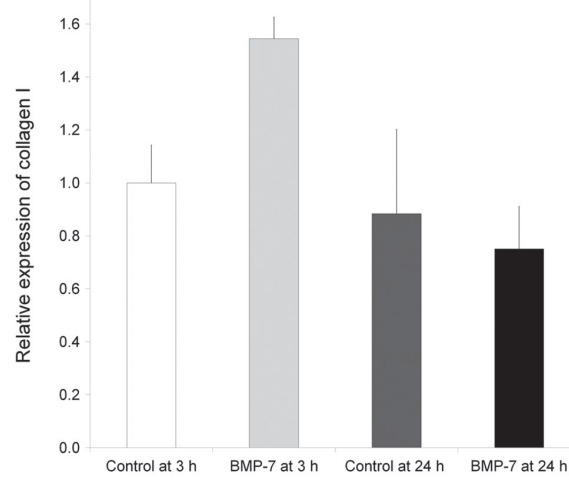

D 1.8

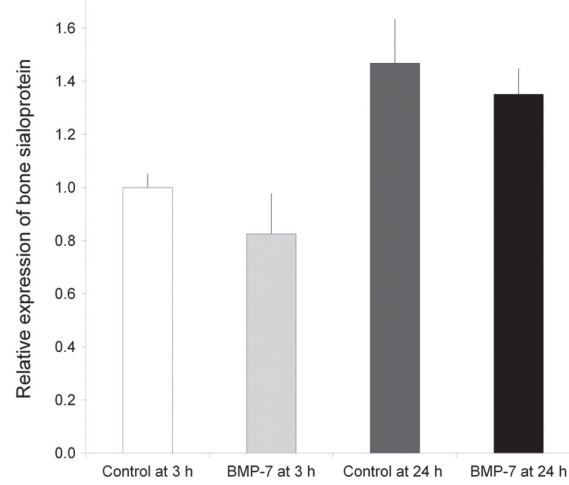

Figure 6. Western blot analysis to evaluate the expression of collagen I, osterix and bone sialoprotein as well as $\beta$-catenin. (A) Evaluation of the protein expressions of collagen I, osterix and bone sialoprotein as well as $\beta$-catenin. (B) Quantitative analysis of the protein expressions of collagen I after normalization with $\beta$-actin levels by densitometry. No statistically significant differences were noted among the groups. (C) Quantitative analysis of the protein expressions of Sp7 after normalization with $\beta$-actin 1 levels by densitometry. No statistically significant changes were observed with the addition of bone morphogenetic protein. (D) Quantitative analysis of the protein expressions of bone sialoprotein after normalization with $\beta$-actin 1 levels by densitometry. No statistically significant differences were detected. BMP-7, bone morphogenetic protein 7. 


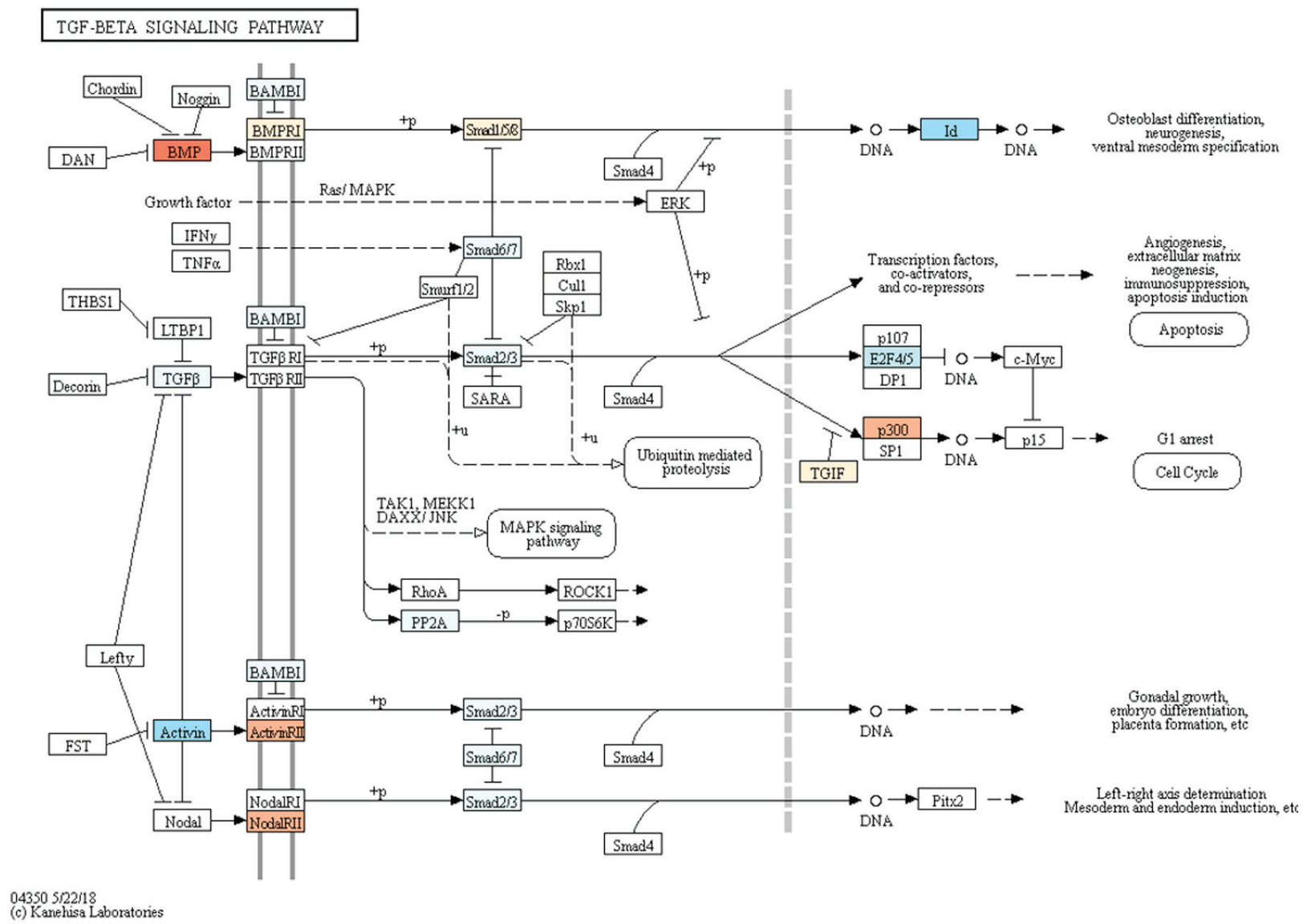

Figure 7. TGF- $\beta$ signaling pathway.

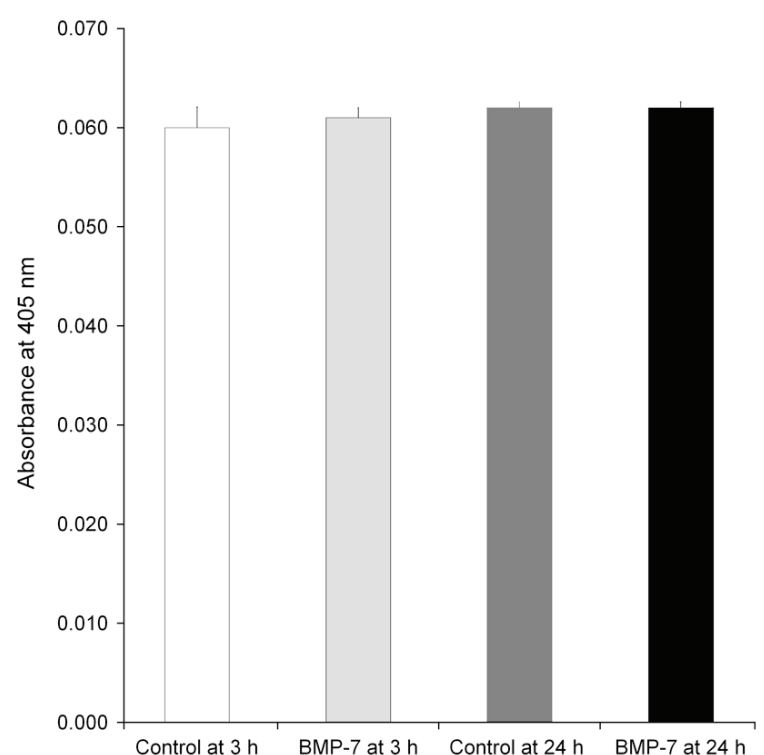

Figure 8. Alkaline phosphatase activity on Day 7. No statistically significant differences were seen between the groups. BMP-7, bone morphogenetic protein 7.

mesenchymal stem cells (22). In a non-union fracture model, BMP-7 expressing mesenchymal stem cells enhanced bone regeneration (20). Similarly, BMP-7 expressing stem cells produced enhanced bone healing in critical-sized defects when compared with the control stem cell sheets (23).
Moreover, application of BMP-7 overexpressing stem cells derived from bone marrow decelerated the development of disc degeneration (21).

It is widely accepted that differentiation of mesenchymal stem cells is associated with gene transcription and courses of molecular signaling (24). Researchers previously used RNA sequencing to analyze transcriptional profiling of osteoblast differentiation (25). Moreover, RNA sequencing and quantitative reverse transcription polymerase chain reactions were applied for characterization of three-dimensional organoids (26). RNA Sequencing has also been applied to compare the differences between mesenchymal stem cells derived from bone marrow from healthy control and diseased participants (27). Researchers previously tested the functionality of mesenchymal stem cells, the precursors of osteoblasts, using RNA sequencing to measure the epigenetic changes with aging (28). This study tested gingiva-derived stem cells' responsiveness to BMP-7 showed differentially expressed mRNA related to osteoblast differentiation in each group.

Researchers previously tested the expression of osteoblast-associated genes and proteins, including COL1A1, Runx2, IBSP, SPARC, SPP1 and BGALP (29). In this study, several gene expressions were tested in mesenchymal stem cells, including Runx2, Sp7 and collagen I (29-31). Researchers previously demonstrated that romidepsin promoted osteogenic differentiation of human mesenchymal stem cells and that it showed increased SP7 (Osterix) and 
alkaline phosphatase expression (32). They also showed that transfection of Runx2/SP7 enhanced the osteogenic differentiation of mesenchymal stem cells (33). This study showed that BMP-7 upregulates genes related to osteoblast differentiation, including collagen I, in gingiva-derived stem cells. Alkaline phosphatase activity is considered an early-stage marker for osteoblast differentiation, the lack of difference may be dues to various reasons including the treatment time of BMP-7 and the stage of tested cells $(34,35)$.

Conclusively, the effects of BMP-7 on stem cells were assessed using mRNA sequencing, and the validation of the expression was done with quantitative real-time polymerase chain reactions and Western blot analysis. The short-term application of BMP-7 produced an increased expression of collagen I, which was related to target genes chosen for osteoblast differentiation. This study may provide new insights into the role of BMP-7 using mRNA sequencing.

\section{Acknowledgements}

Not applicable.

\section{Funding}

The present study was supported by Basic Science Research Program through the National Research Foundation of Korea (NRF) funded by the Ministry of Science, Information and Communication Technology \& Future Planning (Grant no. NRF-2017R1A1A1A05001307).

\section{Availability of data and materials}

All data generated or analyzed during this study are included in this published article.

\section{Authors' contributions}

HL, SM, YS, YP, and JP contributed to study conception and design. HL, SM, YS, YP, and JP performed the experiments; HL, SM, YS, YP, and JP analyzed the data and HL, SM, YS, YP, and JP wrote the manuscript. All authors reviewed the manuscript.

\section{Ethical approval and consent to participate}

The protocol of the study was reviewed and the Institutional Review Board of the Catholic University of Korea, College of Medicine approved the design of this study (KC18SESI0199). Written informed consent was gathered from the participants according to the Act on Legal Codes for Biomedical Ethics and Safety and the Declaration of Helsinki.

\section{Patient consent for publication}

Not applicable.

\section{Competing interests}

The authors declare that they have no competing interests.

\section{References}

1. Park JB: Use of bone morphogenetic proteins in sinus augmentation procedure. J Craniofac Surg 20: 1501-1503, 2009.

2. Park JB: Effects of the combination of fibroblast growth factor-2 and bone morphogenetic protein-2 on the proliferation and differentiation of osteoprecursor cells. Adv Clin Exp Med 23: 463-467, 2014

3. Zhu L, Ma J, Mu R, Zhu R, Chen F, Wei X, Shi X, Zang S and Jin L: Bone morphogenetic protein 7 promotes odontogenic differentiation of dental pulp stem cells in vitro. Life Sci 202: 175-181, 2018.

4. Chen F, Bi D, Cao G, Cheng C, Ma S, Liu Y and Cheng K: Bone morphogenetic protein 7-transduced human dermal-derived fibroblast cells differentiate into osteoblasts and form bone in vivo. Connect Tissue Res 59: 223-232, 2018.

5. Jovanovic VM, Salti A, Tilleman H, Zega K, Jukic MM, Zou H, Friedel RH, Prakash N, Blaess S, Edenhofer F and Brodski C: BMP/SMAD pathway promotes neurogenesis of midbrain dopaminergic neurons in vivo and in human induced pluripotent and neural stem cells. J Neurosci 38: 1662-1676, 2018.

6. Soundara Rajan T, Giacoppo S, Scionti D, Diomede F, Grassi G, Pollastro F, Piattelli A, Bramanti P, Mazzon E and Trubiani O: Cannabidiol activates neuronal precursor genes in human gingival mesenchymal stromal cells. J Cell Biochem 118: 1531-1546, 2017.

7. Ansari S, Diniz IM, Chen C, Sarrion P, Tamayol A, Wu BM and Moshaverinia A: Human periodontal ligament- and gingiva-derived mesenchymal stem cells promote nerve regeneration when encapsulated in alginate/hyaluronic acid 3D scaffold. Adv Healthc Mater 6: 2017.

8. Zhang Q, Nguyen PD, Shi S, Burrell JC, Cullen DK and Le AD: 3D bio-printed scaffold-free nerve constructs with human gingiva-derived mesenchymal stem cells promote rat facial nerve regeneration. Sci Rep 8: 6634, 2018.

9. Yang R, Yu T, Liu D, Shi S and Zhou Y: Hydrogen sulfide promotes immunomodulation of gingiva-derived mesenchymal stem cells via the Fas/FasL coupling pathway. Stem Cell Res Ther 9: 62, 2018.

10. Wang F, Yu M, Yan X, Wen Y, Zeng Q, Yue W, Yang P and Pei X: Gingiva-derived mesenchymal stem cell-mediated therapeutic approach for bone tissue regeneration. Stem Cells Dev 20: 2093-2102, 2011.

11. Lee SI, Ko Y and Park JB: Evaluation of the shape, viability, stemness and osteogenic differentiation of cell spheroids formed from human gingiva-derived stem cells and osteoprecursor cells. Exp Ther Med 13: 3467-3473, 2017.

12. Jin SH, Lee JE, Yun JH, Kim I, Ko Y and Park JB: Isolation and characterization of human mesenchymal stem cells from gingival connective tissue. J Periodontal Res 50: 461-467, 2015.

13. Trapnell C, Pachter L and Salzberg SL: TopHat: Discovering splice junctions with RNA-Seq. Bioinformatics 25: 1105-1111, 2009.

14. Quinlan AR and Hall IM: BEDTools: A flexible suite of utilities for comparing genomic features. Bioinformatics 26 : 841-842, 2010

15. Gentleman RC, Carey VJ, Bates DM, Bolstad B, Dettling M, Dudoit S, Ellis B, Gautier L, Ge Y, Gentry J, et al: Bioconductor: Open software development for computational biology and bioinformatics. Genome Biol 5: R80, 2004.

16. Huang DW, Sherman BT, Tan Q, Collins JR, Alvord WG, Roayaei J, Stephens R, Baseler MW, Lane HC and Lempicki RA: The DAVID gene functional classification tool: A novel biological module-centric algorithm to functionally analyze large gene lists. Genome Biol 8: R183, 2007.

17. Kanehisa M, Furumichi M, Tanabe M, Sato Y and Morishima K: KEGG: new perspectives on genomes, pathways, diseases and drugs. Nucleic Acids Res 45: D353-D361, 2017.

18. Zhang X, Huang F, Li W, Dang JL, Yuan J, Wang J, Zeng DL, Sun CX, Liu YY, Ao Q, et al: Human gingiva-derived mesenchymal stem cells modulate monocytes/macrophages and alleviate atherosclerosis. Front Immunol 9: 878, 2018.

19. Rajan TS, Scionti D, Diomede F, Piattelli A, Bramanti P, Mazzon E and Trubiani O: Prolonged expansion induces spontaneous neural progenitor differentiation from human gingiva-derived mesenchymal stem cells. Cell Reprogram 19: 389-401, 2017. 
20. Song J, Kim Y, Kweon OK and Kang BJ: Use of stem-cell sheets expressing bone morphogenetic protein-7 in the management of a nonunion radial fracture in a Toy Poodle. J Vet Sci 18: 555-558, 2017.

21. Liao JC: Cell therapy using bone marrow-derived stem cell overexpressing BMP-7 for degenerative discs in a rat tail disc model. Int J Mol Sci 17: E147, 2016.

22. Yan X, Zhou Z, Guo L, Zeng Z, Guo Z, Shao Q and Xu W: BMP7-overexpressing bone marrow-derived mesenchymal stem cells (BMSCs) are more effective than wild-type BMSCs in healing fractures. Exp Ther Med 16: 1381-1388, 2018.

23. Kim Y, Kang BJ, Kim WH, Yun HS and Kweon OK: Evaluation of mesenchymal stem cell sheets overexpressing BMP-7 in canine critical-sized bone defects. Int J Mol Sci 19: E2073, 2018

24. Fakhry M, Hamade E, Badran B, Buchet R and Magne D: Molecular mechanisms of mesenchymal stem cell differentiation towards osteoblasts. World J Stem Cells 5: 136-148, 2013.

25. Khayal LA, Grünhagen J, Provazník I, Mundlos S, Kornak U, Robinson PN and Ott CE: Transcriptional profiling of murine osteoblast differentiation based on RNA-seq expression analyses. Bone 113: 29-40, 2018.

26. Wiener DJ, Basak O, Asra P, Boonekamp KE, Kretzschmar K, Papaspyropoulos A and Clevers H: Establishment and characterization of a canine keratinocyte organoid culture system. Vet Dermatol 29: 375-e126, 2018.

27. Sargent A, Shano G, Karl M, Garrison E, Miller C and Miller RH: Transcriptional profiling of mesenchymal stem cells identifies distinct neuroimmune pathways altered by CNS disease. Int J Stem Cells 11: 48-60, 2018

28. Del Real A, Pérez-Campo FM, Fernández AF, Sañudo C, Ibarbia CG, Pérez-Núñez MI, Criekinge WV, Braspenning M, Alonso MA, Fraga MF and Riancho JA: Differential analysis of genome-wide methylation and gene expression in mesenchymal stem cells of patients with fractures and osteoarthritis. Epigenetics 12: 113-122, 2017.
29. Baird A, Lindsay T, Everett A, Iyemere V, Paterson YZ, McClellan A, Henson FMD and Guest DJ: Osteoblast differentiation of equine induced pluripotent stem cells. Biol Open 7: bio033514, 2018.

30. Barone A, Toti P, Funel N, Campani D and Covani U: Expression of SP7, RUNX1, DLX5, and CTNNB1 in human mesenchymal stem cells cultured on xenogeneic bone substitute as compared with machined titanium. Implant Dent 23: 407-415, 2014

31. Hajizadeh N, Madani ZS, Zabihi E, Golpour M, Zahedpasha A and Mohammadnia M: Effect of MTA and CEM on mineralization-associated gene expression in stem cells derived from apical papilla. Iran Endod J 13: 94-101, 2018.

32. Ali D, Chalisserry EP, Manikandan M, Hamam R, Alfayez M, Kassem M, Aldahmash A and Alajez NM: Romidepsin promotes osteogenic and adipocytic differentiation of human mesenchymal stem cells through inhibition of histondeacetylase activity. Stem Cells Int 2018: 2379546, 2018.

33. Kim HJ, Park JS, Yi SW, Oh HJ, Kim JH and Park KH: Sequential transfection of RUNX2/SP7 and ATF4 coated onto dexamethasone-loaded nanospheresenhances osteogenesis. Sci Rep 8: 1447, 2018.

34. Prins HJ, Braat AK, Gawlitta D, Dhert WJ, Egan DA, Tijssen-Slump E, Yuan H, Coffer PJ, Rozemuller H and Martens AC: In vitro induction of alkaline phosphatase levels predicts in vivo bone forming capacity of human bone marrow stromal cells. Stem Cell Res 12: 428-440, 2014.

35. Lu C, Xing Z, Yu YY, Colnot C, Miclau T and Marcucio RS: Recombinant human bone morphogenetic protein-7 enhances fracture healing in an ischemic environment. J Orthop Res 28: 687-696, 2010

(i) () () This work is licensed under a Creative Commons

C) Attribution-NonCommercial-NoDerivatives 4.0 International (CC BY-NC-ND 4.0) License. 